\title{
Synthesis and Characterization of Polycrystalline Cubic Boron Nitride Composites with Al Binder
}

\author{
L. Liu, G.P. Sun, S.S. Xu \\ School of Materials and Chemical Engineering, \\ Zhongyuan University of Technology \\ Zhengzhou, China
}

\begin{abstract}
The PcBN materials were sintered from the cBN-Al systems under high-pressure and high-temperature, and the mechanical properties, composition and microstructure of prepared samples were analyzed. The results show that the microstructure is fairly even and the binding phase is uniformly distributed in its volume. The sintered samples are composed of a large portion of $\mathrm{CBN}$ and of a small portion of $\mathrm{AIN}$, also very little amount of AlB2. And cBN grains are always surrounded by AIN and AIB2 layer which formed three-dimensional networks. It also shows that the hardness of the PcBN composites decreases and the density values increase with Al content increasing.
\end{abstract}

Keywords-PcBN; microstructur; high pressure high temperature; composites

\section{INTRODUCTION}

Cubic boron nitride $(\mathrm{cBN})$ is the second hardest material after diamond and shows low-reactivity with ferrous materials. Therefore, $\mathrm{cBN}$ is used as a cutting tool in high-speed machining of hard she use of binders and high-pressure, high temperature (HPHT) conditions is the method of choice teel and cast iron and in the form of a composite material, polycrystalline cubic boron nitride $(\mathrm{PcBN})$ material, in cutting operations. PcBN tool materials with outstanding properties such as high hardness, high thermal stability and conductivity, and adequate toughness have revolutionized machining of hard ferrous materials [1-2].

The use of binders and HPHT conditions is the method of choice for sintering PcBN materials with temperatures and pressures in the range of $1200-1500^{\circ} \mathrm{C}$ and $4-7 \mathrm{GPa}$, respectively. Metals of the groups IV, V and VI of the periodic table or their compounds or other metallic elements such as aluminium, cobalt and nickel are used as binders to aid sintering [3-6]. Chemical reactions between them and boron nitride occur, resulting in the formation of some new phases. It is important to know the mechanical properties and sintering mechanisms of polycrystalline $\mathrm{cBN}$ materials in order to fully understand the behavior of these materials in an application.

Among metals, aluminium is the most frequently used as a binding material for the sintering of cubic boron nitride with other elements. In this work, PcBN materials were sintered from the cBN-Al systems under HPHT. The effect of $\mathrm{Al}$ content on mechanical properties, composition and microstructure of as-prepared composites were studied.

\section{EXPERIMENTAL PROCEDURES}

The starting materials used in this experiment were $\mathrm{cBN}$ powder (Zhengzhou Zhongnan Jete Superabrasives Co., Ltd, China) with the granularity mixture $(40 \% \mathrm{~W} 10+30 \% \mathrm{~W} 7+30 \% \mathrm{~W} 4)$ and aluminum micro-powder (an average particle size 5um, $>99.6 \%$ purity, Shanghai stnano science and technology Co., Ltd, China). The micropowders were manually mixed using an agate mortar and pestle for $2 \mathrm{~h}$, at a proportion of 5, 8,10 and $12 \mathrm{wt} \% \mathrm{Al}$ in cBN-Al system, respectively. The mixed micro-powders were prepared in a cubic anvil high-pressure apparatus at $1350^{\circ} \mathrm{C}$ under a pressure of about 5.4 GPa. After keeping the sample at this temperature for 5 minutes, the temperature decreased rapidly by turning off the electric power, and then the pressure was unloaded. The sintered samples were ground with a diamond grinding wheel to a smooth mirror surface.

Prepared PcBN was then characterized. X-ray diffraction (XRD) was performed in a Rigaku Ultima IV-type diffractometer to identify existing phases in sintered samples, using $\mathrm{CuK} \alpha$ radiation with the angular between 20 and $70^{\circ}$. Microstructure was examined by the JSM-6360LV scanning electronic microscope (SEM). Hardness measurements were made with Vicher 402MVD hardness tester by indentation using a pyramidal indenter and applying a $9.8 \mathrm{~N}$ load for $10 \mathrm{~s}$. And densities were measured with MDY-350 digital densimeter.

\section{RESULTS AND DISCUSSION}

XRD patterns of the PcBN compacts sintered from $\mathrm{cBN}-\mathrm{Al}$ system were shown in Fig.1, which reveals the sintered samples are composed of a large portion of $\mathrm{cBN}$ and of a small portion of $\mathrm{AlN}$, also very little amount of $\mathrm{AlB}_{2}$. No diffraction peaks of metallic Al was observed in the sintered samples, which indicates the starting $\mathrm{Al}$ was totally consumed and high reactivity between $\mathrm{Al}$ and $\mathrm{cBN}$ at high temperature and high pressure condition. The reaction formula can be summarized as $3 \mathrm{Al}+2 \mathrm{BN}=2 \mathrm{AlN}+\mathrm{AlB}_{2}$. And the intensity of $\mathrm{AlN}$ and $\mathrm{AlB}_{2}$ gets higher with the aluminum content increasing. 


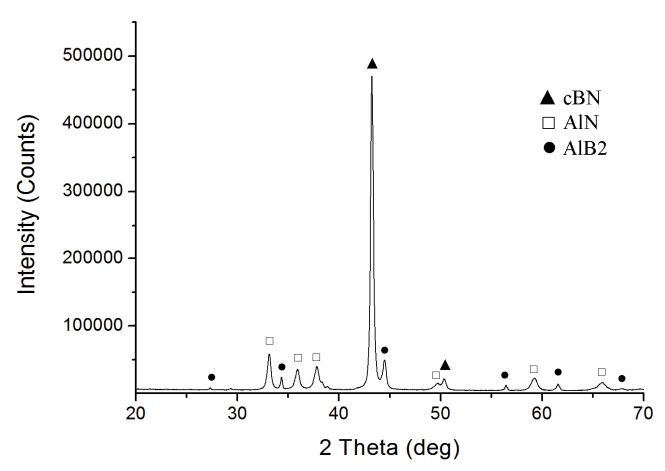

FIGURE I. XRD PATTERNS OF THE PCBN SAMPLE

SEM micrographs of the fracture surface of PcBN sintered were shown in Fig.2. As it can be seen, the microstructure is fairly even and the binding phase is uniformly distributed in its volume. And cBN grains are always surrounded by AlN and $\mathrm{AlB}_{2}$ layer which formed three-dimensional networks. The micrographs do not reveal any detectable pores within this scale suggesting that the material is nearly fully dense. Although not shown here, structural defects namely dislocations and microtwins are probably contained which could influence the mechanical properties of PcBN materials. The patterns of fracture has two general models: transgranular and intergranular. Fracture of PcBN compacts prepared from $\mathrm{cBN}-\mathrm{Al}$ system is dominated by intergranular fracture, which is beneficial to improving the fracture toughness.

Fig.3 shows the relationship of microhardness measurements of the prepared PcBN versus aluminum content. The hardness values show that the $\mathrm{PcBN}$ with $\mathrm{Al} 5 \mathrm{wt} \%$ has the highest hardness of $34.1 \mathrm{GPa}$, while the PcBN with $\mathrm{Al} 12 \mathrm{wt} \%$ has the lowest hardness of $17.3 \mathrm{GPa}$. The hardness of the $\mathrm{PcBN}$ composites decreases with increasing $\mathrm{Al}$ content. This is because that hardness is determined by the amount of the ultra-hard cBN phase. As show in X-ray diffraction patterns that more AlN and AlB2 appeared when the binder phases increase, which caused a lower hardness. At lower content of binder phases there are more $\mathrm{cBN}-\mathrm{cBN}$ contacts thus leading to higher hardness.

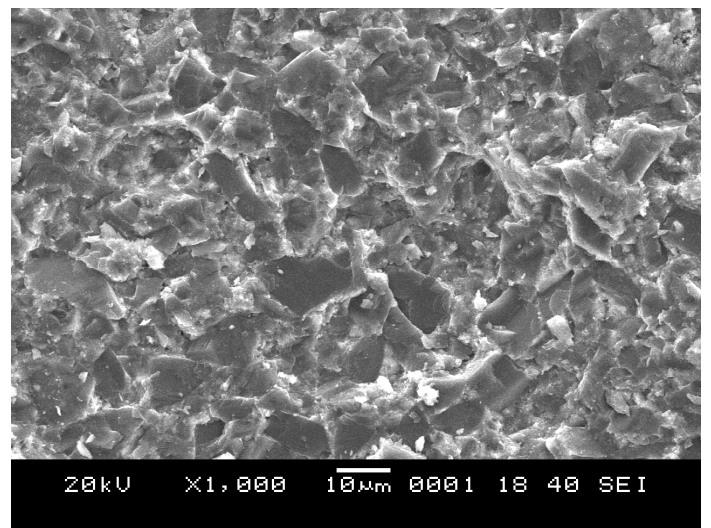

FIGURE II. SEM IMAGE OF THE PCBN SAMPLE

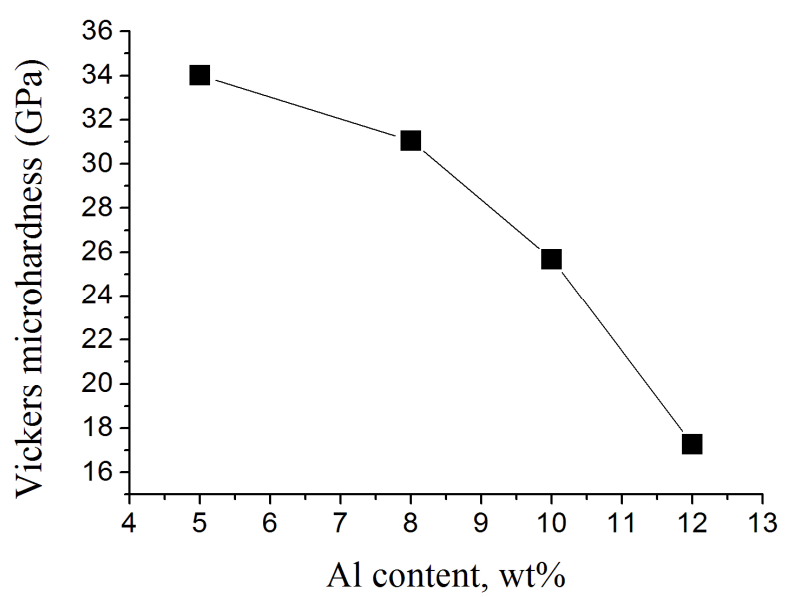

FIGURE III. HARDNESS OF THE PCBN SAMPLES VERSUS AL CONTENT

The density test shows that the density values increased with $\mathrm{Al}$ content increasing in the $\mathrm{cBN}-\mathrm{Al}$ system. A highest density of $3.397 \mathrm{~g} / \mathrm{cm}^{3}$ was obtained with containing $12 \mathrm{wt} \%$ $\mathrm{Al}$ in starting materials, while the density of PcBN containing $5 \mathrm{wt} \% \mathrm{Al}$ is $3.331 \mathrm{~g} / \mathrm{cm}^{3}$. This is because that the reaction phases resulted in a strengthening effect in bonding $\mathrm{cBN}$ grains tightly.

\section{CONCLUSIONS}

PcBN materials were sintered from the cBN-Al systems under HPHT, and the mechanical properties, composition and microstructure of prepared samples were analyzed. The following conclusions were drawn from the test results:

The microstructure is fairly even and the binding phase is uniformly distributed in its volume. The sintered samples are composed of a large portion of $\mathrm{cBN}$ and of a small portion of AlN, also very little amount of $\mathrm{AlB}_{2}$. And $\mathrm{cBN}$ grains are always surrounded by $\mathrm{AlN}$ and $\mathrm{AlB}_{2}$ layer which formed three-dimensional networks. It is shown that the hardness of the PcBN composites decreases and the density values increase with $\mathrm{Al}$ content increasing.

\section{ACKNOWLEDGEMENTS}

The authors would like to thank the Natural Science Foundation of Henan Provincial Education Department (No.14B430031), and the Science and Technology Planning Project of Zhengzhou (No.141PPTGG390) for providing financial support.

\section{REFERENCES}

[1] J. Kopac, P. Krajnik, High-performance grinding-a review. Journal of Materials Processing Technology, 175(1-3), pp. 278-284, 2006.

[2] H. Kato, K. Shintani, H. Sumiya, Cutting performance of a binder less sintered cubic boron nitride tool in the high speed milling of grey cast iron. Journal of Materials Processing Technology, 127, pp. 217-221, 2002.

[3] A. McKie, J. Winzer, I. Sigalas, et al, Mechanical properties of cBN-Al composite materials. Ceramics International, 37 (1), pp. 1-8, 2011. 
[4] E. Benko, P. Klimczyk, S. Mackiewicz, et al, cBN-Ti3SiC2 composites. Diamond and Related Materials, 13(3), pp. 521-525, 2004

[5] X. Z. Rong, T. Tsurumi, O. Fukunagab, T. Yano, High pressure sintering of cBN-TiN-Al composite for cutting tool application. Diamond and Related Materials, 11, pp. 280-286, 2002.

[6] M. A. Umer, P. H. Sub, D. J. Lee, et al, Polycrystalline cubic boron nitride sintered compacts prepared from nanocrystalline TiN coated cBN powder. Materials Science and Engineering A, 552, pp. 151$156,2012$. 